\title{
Critical Thinking Ability and Performance in Argumentative Essays of the Education Major Students*
}

\author{
Fengyi Ma \\ Office of Foreign Languages, Guilin Medical University, China \\ Yuan $\mathrm{Li}^{1}$ \\ Office of Foreign Languages, Guilin Medical University, China
}

\begin{abstract}
The study was carried out to assess the relationship between students' critical thinking abilities and their success in writing an argumentative essay. The descriptive-correlation design was used in this research. The respondents in this survey were a total of 310 Education major students. This is 22.32 percent of the 1387 students enrolled in the Education program. The 50-item questionnaire was based on the Watson-Glaser Critical Thinking Appraisal from Pearson TalentLens to measure the student's study critical thinking abilities. The following conclusions were drawn: the students lack critical thinking ability; the students have difficulty in constructing argumentative essays; and the less critical the students are, the less performance they have in writing argumentative essays.
\end{abstract}

Index Terms - critical thinking abilities, argumentative essay, performance in writing

\section{INTRODUCTION}

Critical thinking is about the capacity to reckon in a rational way on what to understand and what to genuinely think in. Although critical thinking has something to do with uncovering falsities inside of preconceptions, it still does not imply that critical thinkers have to also be critical of some of the other individuals. They just draw appropriate inferences from the evidence. This allows them to participate in collaborative thinking and other valuable pursuits. It aids them in conceptualizing and analyzing issues that would otherwise go unnoticed by others. As a result, understanding when and how to critically analyze a circumstance is a skill that everyone needs to not only acquire but actively practice (Hitchcock, 2018).

A student's ability to think critically is extremely valuable. Whatever career a student chooses to pursue, they will always need the ability to think critically, understand, and assess situations mindfully. This ability is what allows one to solve issues systematically. The knowledge-based market of the twenty-first century moves at a breakneck speed. It is dramatically evolving and being able to think critically and effectively is an excellent way to adapt. When one can think on their toes, they can rapidly incorporate innovative ideas into their task and avoid losing. This is an important characteristic that influences a person's overall capabilities (Lausch, 2018). People with thoughts that are susceptible to analysis and critical thinking can explain even the most ordinary arguments coherently and articulately. This enables them to relate and analyze results much more effectively. They may convey knowledge logically and progressively, helping others to get a better comprehension as well (Alban \& Alban, 2021).

According to Sellar et al. (2019), in the twenty-first century, when concepts demand constructive, logical, and intellectual evolution, critical thinkers are almost certain to prevail. Applying such concepts translates to professional and educational excellence.

Critical thinking is an excellent ability to cultivate. It comes in handy in every circumstance when one must come to any resolution, regardless of whether it is about education, job, or in regular activities.

To think critically regarding anything, one must be able to recognize the rational links within concepts; examine the details that are provided; analyze and evaluate information; check to see if whatever is being taught is correct and real; examine the issue from many perspectives and positions; and evaluate diverse arguments to determine their merits and flaws (Islam, 2015).

Because critical thinking is grounded on knowledge, reasonable analysis, and introspection, it helps one generate informed conclusions. This helps a lot in nearly every scenario. This can, for instance, aid with the interpretation of information. Facts and figures are essential but understanding the origin of the information and the link connecting facts

\footnotetext{
* The Study is supported by Guangxi Higher Education Undergraduate Teaching Reform Project, [grant number 394 2019jgb295]

${ }^{1}$ Corresponding Author
} 
is just as crucial. Thinking critically enables one to spot prejudice and manipulations and create one's well-informed judgments (Rabinowitz, 2021).

Curiosity can also be fostered by critical thinking. By evaluating the content received, one does not have to take what he or she sees or hears at a surface level. Rather, the individual examines the offered viewpoint and investigates the rationale and origins behind it (Lumen Learning, 2016).

Finally, critical thinking enables the person to construct a persuasive argument that is supported by evidence. Assertions built on personal conviction without substantiated proof are frequently invalidated. This ability can be worthwhile while writing essays or debating national issues with others. It enables one to give a nuanced perspective that examines varying viewpoints and means regarding evidence-based ideas (Lumen Learning, 2016).

Cognition skills, along with social inclinations and prejudices, are all part of critical thinking. As a result, it may be challenging to detect Critical Thinking abilities from a résumé or a job application, which is why most companies opt to use psychometric exams as an element of their hiring procedure (DeLecce \& Pisano, 2021).

The Watson-Glaser Critical Thinking Appraisal (2021) from Pearson TalentLens is among the most extensively utilized psychometric evaluations. The Watson-Glaser Critical Thinking Test is a thoroughly challenging assessment and exam that is mainly utilized during the context of staffing to assess critical thinking abilities in employment, institute, and business and management aspirants.

Every Watson-Glaser assessment is made up of instances that are common in several contexts, such as the industry, schools, as well as other social organizations. Several companies utilize the Watson-Glaser Critical Thinking Exam and Development Report to determine an individual's capabilities and training concerns, as well as to offer mentoring initiatives and programs. Each component is made to put varying capabilities to the exam.

These are as follows:

Argument Evaluation is a simple yes/no inquiry. Individuals will be provided with a proposition as well as a viable counterargument. The goal is to determine whether the potential argument may be utilized to support the facts presented

Assumption recognition: the anticipated appropriate response is Yes or No. A citation remark and a presumption based on the citation will be supplied. One needs to evaluate whether the assumption based on the statement is accurate.

Deduction: one will start with a sentence and draw inferences from it. The task is to determine if the inferences make reasonable sense on the facts provided. This sort of inquiry has only two possible answers: yes or no.

Inferences: one needs to obtain the original assertion plus a line derived out of facts in this sort of inquiry. The goal is to figure out how likely it is that the suggested statement is correct. True, false, probably true, probably false, and Insufficient Data are the alternatives you'll be given in this sort of inquiry.

Interpretation: This questionnaire is comparable to a deduction regarding organization. A remark and a resolution will be presented, and one has to figure out if the conclusion's assumption regarding the data is correct. To this issue, one must respond with a yes or a no.

Critical thinking is a fundamental academic technique that enables students to examine and analyze according to their basic knowledge. This ability is necessary for students who are engaging in coursework or conducting studies. This is also an essential skill set in a variety of working situations.

There seem to be multiple interpretations of critical thinking, and according to Beyer (1995), critical thinking is defined as "drawing precise, reasoned judgments."

A good critical thinker investigates the sources of any information, dismisses subjective or quasi-arguments, and challenges perceived knowledge. The individual is open-minded and well-informed, capable of assessing the validity of arguments and reaching careful but concrete proof judgments (Cummings, 2021).

Academic students benefit from it since it allows them to write academic essays that are devoid of subjective or social prejudices. Before employing a type of data as a resource, students must become proficient at evaluating it to establish its value.

Before using a statistic, citation, or research article to justify the claim in an activity or discourse, students need to double-check the material to be sure it came from a credible source. That authority must be backed up by strong facts and free of publication bias.

Lesser scores would be given to papers founded on weak or poorly examined data sources, as the findings reached are only as trustworthy as the evidence they are founded on.

As students learn to analyze data and examine competing ideas, critical thinking develops organically over time.

Mastering to express thoughts in words, on the other hand, is a difficult task for several students. The capacity to think rationally and to formulate judgments is components in developing critical thinking. Writing may be used to assess a student's opportunity to form well-organized arguments (Carlyle, 2018).

According to the National Assessment of Educational Progress (2017), 75\% of American students in grades 12 and 8 have poor writing abilities.

Poor writing abilities among students are not a new thing. Critical thinking has long been a challenge for students, as it is equally hard to teach and complicated to understand. Students who are unable to think critically have a difficult time expressing themselves in writing. It is much more difficult to educate students on how to create and promote an original concept than it is to train them on how to prevent spelling mistakes. Critical thinking entails evaluating, finding solutions, and forming decisions, all of which are important components of a successful essay. 
An argumentative essay is a piece of writing designed to help you develop your analytical abilities. Argumentative essays must train students how to read texts attentively, use systematic skepticism, discover flaws in both others and their arguments, deal with topics, and articulate themselves explicitly and rationally. Asking and answering the correct questions is the foundation of a critical thinking essay. The caliber of the content and how a student builds arguments regarding a certain subject are generally the focus. Positions are built on their study and findings in every instance (Kearney, 2020).

University students are required to write essays as part of their coursework. An argumentative essay, as an example of various paper formats, asks students to use analytical and introspective writing abilities. These abilities highlight crucial elements of a critical thinking essay: information analysis, reflection on significant discoveries; evaluating the material's significance, and identifying any conclusions drawn by the researcher(s) or other experts. As a result, an argumentative essay is a paper that demands students to study materials and interpret them according to their perspectives. To enhance their logical and analytical skills, students must know how to develop a critical thinking essay (Purdue Online Writing Lab, 2021).

Students can determine if an essay they are working on is a critical thinking piece depending on the important elements listed earlier. If the question requires students to read and evaluate a book, learners should be able to tell if their works are critical thinking essays. Essentially, the evaluation phase is thinking about the content, conducting assessments about how the material is conveyed and how it relates to prior knowledge, and either affirming or contesting the conclusions reached. These elements, in concept, represent the characteristics that distinguish a critical thinking essay.

Because studies of the relationship between students' critical thinking abilities and their success in writing an argumentative essay are still rare yet noteworthy, this study was carried out to achieve the research's goal.

\section{Methodology}

The descriptive-correlation design was used in this research. Descriptive-correlation studies, according to Stangor (2011), highlight the components and the fundamental correlations that exist between as well as among them.

The identification, collection, analysis, and interpretation of the current structure and content of the occurrences are all part of the descriptive design (Question Pro, 2021). This method was used to assess the critical thinking ability and argumentative essay writing performance of first-year Education major students.

The correlation design, on the other hand, was utilized to determine the connection between the students' critical thinking skills and their writing performance. The correlation design depicts the relationship between two, or more variables, as well as how one variable differs from another (Bhandari, 2021).

A questionnaire was used to assess the students' critical thinking abilities. Besides, the students had to produce critical thinking essays.

The respondents in this survey were a total of 310 Education major students. This is 22.32 percent of the 1387 students enrolled in the Education program.

Slovin's formula $(n=\mathrm{N} / 1+\mathrm{Ne} 2)$ had been used to compute the sample size, where $\mathrm{n}=$ sample size, N=population size, and $\mathrm{e}=$ margin of error. Each group was given a percentage to achieve the necessary sample size. Furthermore, to draw the participants in each class, simple random selection was used, as this offers an impartial sample of the whole population (Hayes, 2021). The responders were chosen using a computer-generated set of random numbers as a method.

\section{A. Research Instrument}

The 50-item questionnaire was based on the Watson-Glaser Critical Thinking Appraisal from Pearson TalentLens to measure the student's study critical thinking abilities. The questionnaire was modified based on the reviewers' and statistician's comments. Part I covers the five aspects of critical thinking: evaluating arguments, assumptions, deductions, inferences, and information interpretation.

The questions are organized as follows: analyzing arguments (statement numbers 1-10), assumptions (statement numbers 11-20), deductions (statement numbers 21-30), inferences (statement numbers 31-40), and interpreting information (statement numbers 41-50). The questionnaire was graded on a 5-point Likert scale, with 1 being the least critical and 5 being the most critical. A Likert Scale is a psychometric scale used in questionnaire-based research (Jamieson, 2017).

The questionnaire was extensively analyzed and changed until it was all properly revised. Furthermore, the students' argumentative essay results were derived from the tasks they completed in their various writing activities in their English class.

The students were given the 50-item critical thinking ability questionnaire, which had been approved by the expert panel, using Google forms. The students' email addresses were used to send the link. The students were given one day to access and complete the survey. Based on the number of participants who responded, the results from the questionnaire were analyzed descriptively. By integrating Google forms to Google spreadsheets, the researcher could measure frequency and determine the mean ratings.

Pearson-Product Moment Correlation (Pearson r) was employed to identify the relationship between the students' critical thinking ability and writing performance. 


\section{B. Statistical Treatment}

The surveys and ratings were digitized and processed using Microsoft Excel to arrange, tally, summarize, and interpret data. The data were submitted to mean and Pearson Product-Moment Correlation tests (Pearson r).

The mean was calculated using the following method to reflect the students' critical thinking ability:

$$
\begin{aligned}
& \mathrm{x}^{-}=f \mathrm{x} / \mathrm{N} \\
& \text { Where: } \mathrm{x}^{-}=\text {mean } \\
& f=\text { frequency } \\
& \mathrm{x}=\text { weight of the score } \\
& \mathrm{N}=\text { number of cases }
\end{aligned}
$$

To interpret the critical thinking ability of the students, the scale below was used:

Scoring Interpretation in the Critical Thinking Ability of the First Year Education Major Students

$\begin{array}{ll}\text { Mean Scores } & \text { Interpretations } \\ 4.50-5.00 & \text { Extremely critical } \\ 3.50-4.49 & \text { Very critical } \\ 2.50-3.49 & \text { Moderately critical } \\ 1.50-2.49 & \text { Slightly critical } \\ 1.00-1.49 & \text { Not critical at all }\end{array}$

To describe the performance in argumentative essays of the students, the scale below was utilized:

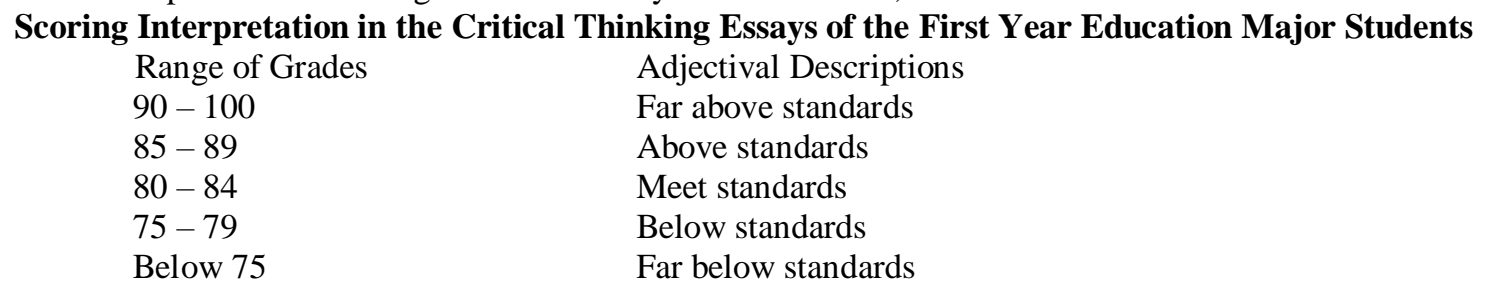

Pearson Product-Moment Correlation is a statistical method for determining the relationship between two variables. A coefficient is a metric for determining the degree of linearity between two variables (Sicat, 2008). As a result, Pearson, r, at the 0.05 level of significance, was used to determine the relationship between the participants' critical thinking ability and performance in argumentative essays.

$$
r=\frac{\sum\left(x_{i}-\bar{x}\right)\left(y_{i}-\bar{y}\right)}{\sqrt{\sum\left(x_{i}-\bar{x}\right)^{2} \sum\left(y_{i}-\bar{y}\right)^{2}}}
$$

\section{Ethical Consideration}

The researcher notified all participants of the study's objective and the relevance of its conclusions. Involvement was optional, and there was no inducement to be applied to the student's grades for engaging in the data collection, as indicated in a permission form issued online. Besides, the researcher guaranteed secrecy and allowed for voluntary disengagement from the study at any time throughout its administration without any need to explain any bias. Informed Consent. Before the data gathering, the parents of the respondents were called and oriented for them to be made aware of the things that their child will be doing. They were asked to sign a written consent form on their own free will to determine if they would permit their child to participate or not.

\section{RESULTS AND FINDINGS}

Table 1 shows the overall grand mean of the critical thinking ability of the students.

TABLE 1

CRITICAL THINKING ABILITy OF THE STUDENTS

\begin{tabular}{|l|l|l|}
\hline Sections & Grand Mean & Verbal Description \\
\hline Analyzing Arguments & 2.42 & Slightly critical \\
\hline Assumptions & 2.39 & Slightly critical \\
\hline Deductions & 2.83 & Moderately critical \\
\hline Inferences & 2.33 & Slightly critical \\
\hline Interpreting Information & 2.40 & Slightly critical \\
\hline Overall Grand Mean & $\mathbf{2 . 4 7}$ & Sometimes \\
\hline
\end{tabular}


Deductions had the greatest grand mean of 2.83, with a verbal description of moderately critical, as seen in the table. This indicates that the student's critical thinking abilities are average in this area. Inferences, on the other hand, had the lowest grand mean of 2.33, and a verbal description of being mildly critical. This shows that the students have performed fairly in this area. It also is worth mentioning that four (4) of the five (5) categories of critical thinking skills examined had mean scores ranging from 2.33 to 2.42 , with verbal descriptors of slightly critical

The student's critical thinking skills received an overall grand mean of 2.47 , with a verbal description of slightly critical, in connection to the findings. As the data demonstrate, students are far less critical. As the data demonstrate, students are far less critical.

The findings were comparable to those of Rupa (2013), who found that elementary and secondary school learners in Bangladesh lacked critical thinking skills. She connects the findings to their region's out-of-date educational system, the inadequacy of enforcement of current educational programs, and educators' incapacity to help learners think critically.

Flores et al. (2010) conducted a further study to investigate the application of critical thinking abilities among students. Critical thinking abilities were said to be lacking among the students. Students were not trained critically and were unprepared for their respective professions. Previous research has shown that managers with weak cognitive processing skills are less successful. As critical thinking is connected to constructivism, leadership, and education, many definitions of critical thinking are reviewed to establish a general construct to guide the debate. Most of the pedagogy, according to the research, is content-driven and focused on deep knowledge.

Non-critical thinkers, as per Ruggiero (2012), are seeing a relatively small number of viewpoints (often just one); consider taking the first method that comes to mind; make judgments quickly - quite instantly and without critical thinking; fail to respond effectively; believe their insights are the best-all others are inferior; resist change; thinking biases and mislead themselves frequently.

Table 2 displays the performance in argumentative essays of the students.

TABLE 2

PERFormanCE In ARGUMENTATIVE ESSAYS OF THE STUDENTS

\begin{tabular}{|l|l|l|l|l|l|l|}
\hline Academic Achievement & C1 & C2 & C3 & C4 & Total & Percentage \\
\hline Far above standards (81-100) & 2 & 4 & 7 & 9 & 22 \\
\hline Above standards (61-80) & 5 & 7 & 11 & 14 & 37 \\
\hline Meet standards (41-60) & 20 & 31 & 30 & 28 & 109 \\
\hline Below standards (21-40) & 43 & 38 & 36 & 25 & 142 \\
\hline $\begin{array}{l}\text { Far below standards } \\
\text { (20 and below) }\end{array}$ & 0 & 0 & 0 & 0 & & 0 \\
\hline Total & $\mathbf{7 0}$ & $\mathbf{8 0}$ & $\mathbf{8 4}$ & $\mathbf{7 6}$ & $\mathbf{3 1 0}$ & \\
\hline
\end{tabular}

According to the data, 142 pupils (45.81\%) achieved a performance level in cr argumentative essays ranging from 21 to 40 , which is considered below standard. Class 1,2,3, and 4 each have forty-three (43), thirty-eight (38), thirty-six (36) and twenty-five (25) students, accordingly. Only twenty-two (22) students, or 7.10 percent, received a level of performance in argumentative essays ranging from 90 to 100, which is considered far above average. Two (2), four (4), seven (7), and nine (9) of the 22 students are from Classes 1, 2, 3, and 4, respectively. Most of the students obtained scores below the standards. This implies that students have poor performance in their argumentative essays.

Alidmat and Ayassrah (2017) investigated how critical thinking abilities may be developed in ESP courses using properly selected English writing exercises. In-depth was utilized as the instrument in the qualitative investigation. The study's results demonstrated that there is little correlation between writing activities in an ESL program and argumentative essays. This is because the program's writing exercises emphasize mechanical writing rather than critical thought.

Table 3 presents the relationship between critical thinking ability and performance in argumentative essays of the students.

TABLE 3

RELATIONSHIP BETWEEN CRITICAL THINKING ABILITY AND PERFORMANCE IN ARGUMENTATIVE ESSAYS OF THE STUDENTS

\begin{tabular}{|c|c|c|c|}
\hline Variables & $\begin{array}{l}\text { Computed } \\
\text { Pearson } \\
\text { r-value }\end{array}$ & Decision & Result \\
\hline Analyzing Arguments & 0.42713 & Reject $\mathrm{H}_{\mathrm{o}}$ & Significant \\
\hline Assumptions & 0.38847 & Reject $\mathrm{H}_{\mathrm{o}}$ & Significant \\
\hline Deductions & 0.44808 & Reject $\mathrm{H}_{\mathrm{o}}$ & Significant \\
\hline Inferences & 0.45657 & Reject $\mathrm{H}_{\mathrm{o}}$ & Significant \\
\hline Interpreting Information & 0.37604 & Reject $\mathrm{H}_{\mathrm{o}}$ & Significant \\
\hline
\end{tabular}

$\mathrm{CV}=0.111557, \quad=0.05 @ \mathrm{DF}=308$

The null hypothesis is rejected based on the data in Table 3, since the computed Pearson R-values are larger than the interpolated critical value of 0.111557 with degrees of freedom (df) of 308 at a 0.05 level of significance. This indicates that students' critical thinking skills and success in argumentative essays are highly correlated.

Thinking and writing, according to Rahmat (2020), are interrelated. Learners' writing skills are similar to what they go through when they think critically. 
This is consistent with the results of Saputra (2018), who found a positive correlation between students' critical thinking and their writing success after doing data analysis. Furthermore, students' critical thinking had a substantial impact on their writing success.

Furthermore, this supports Dixon, Cassady, Cross, and Williams' (2005, p. 181) assertion that writing provides a medium for students to easily communicate their critical thinking. Cosgrove (2011) also stated that learning to think critically involves reflection and conveying one's thoughts to others by conversing, writing, or acting. They emphasize that when students are taught to utilize a critical thinking approach systematically in writing, writing will appear to be a manifestation of critical thinking.

All of the critical thinking subscales (inference, assumptions, deductions, interpretation, and arguments) were positively and significantly correlated with argumentative writing, according to Hashemi, Behrooznia, and Mahjoobi (2010). The reasons for this were that students with stronger critical thinking skills also had superior argumentative writing skills. Students who lack critical thinking skills, on the other hand, underperform in their writing.

\section{CONCLUSION}

Based on the findings of the study, the following conclusions were drawn: the students lack critical thinking ability; the students have difficulty in constructing argumentative essays; and the less critical the students are, the less performance they have in writing argumentative essays.

\section{ACKNOWLEDGEMENTS}

The author wishes to thank the study participants for their contribution to the research, as well as the current and past investigators and staff.

\section{REFERENCES}

[1] Alban, P. \& Alban, D. (2021). Why Critical Thinking is Important (\& How to Improve It). Be Brain Fit. Retrieved August 25, 2021, from https://bebrainfit.com/critical-thinking/

[2] Alidmat, A. \& Ayassrah, M. (2017). Development of Critical Thinking Skills through Writing Tasks: Challenges Facing Maritime English Students at Aqaba College, AlBalqa Applied University, Jordan. Research Gate. Retrieved September 10, 2021 , from

https://www.researchgate.net/publication/317115386_Development_of_Critical_Thinking_Skills_through_Writing_Tasks_Cha llenges_Facing_Maritime_English_Students_at_Aqaba_College_AlBalqa_Applied_University_Jordan

[3] Beyer, B. (1995). Thought and Thinking. Critical Thinking. Humanitas Educational Publishing House

[4] Bhandari, P. (2021). An introduction to correlational research. Scribbr. Retrieved August 10, 2021, from https://www.scribbr.com/methodology/correlational-research/

[5] Carlyle, J. (2018). How Essay Writing Can Enhance Your Critical Thinking Skills. American Board Blog. Retrieved September 1, 2021, from https://www.americanboard.org/blog/how-essay-writing-can-enhance-your-critical-thinking-skills/

[6] Cosgrove, R. (2011). Improving Teaching and Learning of Critical Thinking across the Curriculum at a Large Research University: An Empirical Study Using Qualitative Methods. University of Cambridge Press. Retrieved September 1, 2021, from https://www.criticalthinking.org/data/pages/45/d62c0654702626eac6a4504f8042a50a52408a877fe4f.pdf

[7] Cummings, R. (2021). Critical Thinking \& Reasoning: Logic and the Role of Arguments. Lumen Learning. Retrieved August 10, 2021, from https://courses.lumenlearning.com/sac-publicspeaking/chapter/chapter-6-logic-and-the-role-of-arguments/

[8] DeLecce, T., \& Pisano, G. (2021). What is Critical Thinking? - Definition, Skills \& Meaning. Study. Com. Retrieved August 10, 2021, from https://study.com/academy/lesson/what-is-critical-thinking-definition-skills-meaning.html

[9] Dixon, F., Cassady, J., Cross, T., \& Williams, D. (2005). Effects of Technology on Critical Thinking and Essay Writing Among Gifted Adolescents. Sage Publication. Retrieved August 10, 2021, from https://journals.sagepub.com/doi/abs/10.4219/jsge2005-482

[10] Flores, K., Matkin, G., Burbach, M., Quinn, C., \& Harding, H. (2010). Deficient Critical Thinking Skills among College Graduates: Implications for leadership. Wiley Online Library. Retrieved August 10, 2021, from https://onlinelibrary.wiley.com/doi/abs/10.1111/j.1469-5812.2010.00672.x

[11] Hashemi, A., Naderi, E., Shariatmadari, A., Seif Naraghi, M., \& Mehrabi, M. (2010). Science production in Iranian educational system by the use of critical thinking. International Journal of Instruction. Retrieved August 28, 2021, from https://files.eric.ed.gov/fulltext/ED522933.pdf

[12] Hayes, A. (2021). Simple Random Sample. Investopedia. Retrieved September 5, 2021, from https://www.investopedia.com/terms/s/simple-random-sample.asp

[13] Hitchcock, D. (2018). Critical Thinking. The Stanford Encyclopedia of Philosophy (Fall 2020 Edition). Retrieved August 26, 2021, from https://plato.stanford.edu/entries/critical-thinking/

[14] Islam, R. (2015). What are the Importance and Benefits of "Critical Thinking Skills"?. Linked In. Retrieved August 26, 2021, from https://www.linkedin.com/pulse/what-importance-benefits-critical-thinking-skills-islam

[15] Jamieson, S. (2017). Likert scale. Britannica. Retrieved August 10, 2021, from https://www.britannica.com/topic/Likert-Scale

[16] Kearney, V. (2020). How to Write an Argumentative Essay Step by Step. Owlcation Academia. Retrieved August 5, 2021, from https://owlcation.com/academia/How-to-Write-an-Argument-Essay

[17] Lausch, S. (2018). Inviting Mindful Silence into Pedagogy: Supporting Agency, Voice, And Critical Engagement Through Silence. Scholar Works Boise State University Graduate College. Retrieved August 10, 2021, from https://scholarworks.boisestate.edu/cgi/viewcontent.cgi?article=2494\&context=td 
[18] Lumen Learning. (2016). Chapter 7: Critical Thinking and Evaluating Information. Lumen Learning. Retrieved August 5, 2021, from https://courses.lumenlearning.com/austincc-learningframeworks/chapter/chapter-7-critical-thinking-and-evaluatinginformation/

[19] National Assessment of Educational Progress. (2017). National Center for Education Statistics. NCES. Retrieved September 5, 2021, from https://nces.ed.gov/nationsreportcard/writing/

[20] Purdue Online Writing Lab. (2021). Argumentative Essays. Purdue University. Retrieved August 10, 2021, from https://owl.purdue.edu/owl/general_writing/academic_writing/essay_writing/argumentative_essays.html

[21] Question Pro. (2021). Descriptive Research: Definition, Characteristics, Methods, Examples and Advantages. Question Pro. Retrieved August 15, 2021, from https://www.questionpro.com/blog/descriptive-research/

[22] Rabinowitz, P. (2021). Section 2. Thinking Critically. Community Tool Box. Retrieved August 5, 2021, from https://ctb.ku.edu/en/table-of-contents/analyze/analyze-community-problems-and-solutions/think-critically/main

[23] Rahmat, N. (2020). Thinking about Thinking in Writing. Research Gate. Retrieved August 10, 2021, from https://www.researchgate.net/publication/338816610_THINKING_ABOUT_THINKING_IN_WRITING

[24] Ruggiero, V. (2012). The art of thinking: A guide to critical and creative thought (10th ed.). Academia. Retrieved August 5, 2021, from https://www.academia.edu/7425475/The_Art_of_Thinking_A_Guide_to_Critical_and_Creative_Thought

[25] Rupa, T. (2013). Lack of Critical Thinking Ability Among the Primary and High School Students of Bangladesh and its Effects on their Tertiary Level Education and Employment Prospects. GRIN. Retrieved September 12, 2021, from https://www.grin.com/document/351056

[26] Saputra, A. (2018). The Correlation Between Critical Thinking and Writing Achievement of the Fifth Semester Students of English Education Study Program of Uin Raden Fatah Palembang. Research Gate. Retrieved August 10, 2021, from https://www.researchgate.net/publication/325869367_THE_CORRELATION_BETWEEN_CRITICAL_THINKING_AND_W RITING_ACHIEVEMENT_OF_THE_FIFTH_SEMESTER_STUDENTS_OF_ENGLISH_EDUCATION_STUDY_PROGRA M_OF_UIN_RADEN_FATAH_PALEMBANG

[27] Sellars, M., Fakirmohammad, R., Bui, L., Fishetti, J., Niyozov, S., Reynolds, R., Ali, N. (2018). Conversations on Critical Thinking: Can Critical Thinking Find Its Way Forward as the Skill Set and Mindset of the Century?. Education Sciences. Retrieved August 11, 2021, from https://www.mdpi.com > pdf-vor

[28] Stangor, C. (2011). Stangor (2.2) Psychologists Use Descriptive, Correlational, and Experimental Research Designs. Canvas Network. Retrieved Aug 28, 2021, from https://learn.canvas.net/courses/65/pages/stangor-2-dot-2-psychologists-usedescriptive-correlational-and-experimental-research-designs

[29] Talent Lens. (2021). Watson Glaser Critical Thinking Appraisal. Pearson. Retrieved August 11, 2021, from https://www.talentlens.com/uk/recruitment/assessments/watson-glaser-critical-thinking-appraisal.html

Fengyi Ma was born in Guangxi, China. She received her Ed.D degree in education from Tarlac State University, the Philippines, in 2020 .

She is currently an associate professor in the Office of Foreign Languages, Guilin Medical University, Guilin, China. Her res earch interests include education and English.

Yuan Li, Corresponding Author, was born in Guangxi, China. She received her Master of Arts in Language and Literature from South China University of Technology, China. She is currently pursuing a doctorate in philosophy of education at Holy Angel University, Philippines.

She is currently a lecturer in the Office of Foreign Languages, Guilin Medical University, Guilin, China. Her research intere sts include English teaching. 